\title{
Investigation of the Regulation of the Escherichia coli btuB Gene Using Operon Fusions
}

\author{
By ANTHONY J. P. FLETCHER, ${ }^{1}$ ANTHONY P. PUGSLEY ${ }^{2}$ AND \\ ROBERT E. GLASS ${ }^{1 *}$ \\ ${ }^{1}$ Department of Biochemistry, Queen's Medical Centre, Clifton Boulevard, Nottingham, \\ NG7 2UH, UK \\ ${ }^{2}$ Unite de Génétique Moléculaire, Institut Pasteur, 28 rue du Dr Roux, 75724 Paris Cedex 15, \\ France
}

(Received 14 February 1986; revised 15 May 1986)

\begin{abstract}
Operon fusions were isolated between $\mathrm{Mu} \mathrm{dX}\left(\operatorname{lac} \mathrm{Cm}^{\mathrm{R}} \mathrm{Ap}{ }^{\mathrm{R}}\right)$ and $b t u B$, the gene encoding the multivalent vitamin $B_{12}$ outer membrane receptor. Using these fusions, vitamin $B_{12}$-mediated repression of btuB in Escherichia coli was demonstrated. Mutations in met $H$, metE and ompR as well as exogenous methionine, membrane pertubants, high osmolar conditions and temperature had no major effect on the expression of the btuB gene.
\end{abstract}

\section{INTRODUCTION}

In Escherichia coli, vitamin $\mathrm{B}_{12}$ is required as a cofactor by the met $H$-encoded homocysteine transmethylase (Taylor \& Weissbach, 1967) and by ethanolamine ammonia lyase (Chang \& Chang, 1975). Of the two enzymes capable of methylating homocysteine to yield methionine, one is vitamin $B_{12}$-dependent and the second, the met $E$ product, functions without the vitamin. Synthesis of the outer membrane BtuB receptor is necessary for uptake of exogenous vitamin $B_{12}$ (Kadner \& Liggins, 1973). Previous studies have suggested that vitamin $B_{12}$ is involved in the repression of the btuB gene (Kadner, 1978), and there is good evidence that vitamin $B_{12}$, in the presence of the met $H$ and $m e t F$ gene products, represses the gene encoding the MetE homocysteine transmethylase (Mulligan et al., 1982). In short, it would appear that under conditions where the level of vitamin $B_{12}$ within the bacterium is sufficient to satisfy the requirements for this cofactor (through uptake via the system involving the BtuB receptor), there is a reduction in the synthesis of both the BtuB receptor and the inefficient met $E$-encoded enzyme. In order to further our understanding of vitamin $B_{12}$-mediated gene regulation, we have isolated operon fusions between $b t u B$ and lacZ making use of $\mathrm{Mu} \mathrm{dX}$ (lac $\mathrm{Cm}^{\mathrm{R}} \mathrm{Ap}^{\mathrm{R}}$ ) (Baker $e t$ $a l .$, 1983). We report the effect of a number of different parameters on the control of btuB expression.

\section{METHODS}

The btuB-lacZ operon fusions were initially isolated by $\mathrm{Mu} \mathrm{dX}\left(\right.$ lac $\mathrm{Cm}^{\mathrm{R}} \mathrm{Ap}^{\mathrm{R}}$ ) infection of PAP 488 [rpsL $\Delta($ lac-pro $)$ ] with selection for $\mathrm{Ap}^{\mathrm{R}}, \mathrm{Cm}^{\mathrm{R}}$ and, following overnight incubation in $\mathrm{L}$ broth, resistance to colicin E2 on lactose-MacConkey agar plates. The $\mathrm{Btu}^{-}$phenotype of $\mathrm{Lac}^{+}$clones was demonstrated by resistance to colicins E1 to E8 and phage BF23, and by the inability to detect the BtuB protein by SDS-PAGE of outer membrane preparations (Pugsley \& Oudega, 1986). The presence of $\mathrm{Mu} \mathrm{dX}$ in btuB was confirmed by showing that, first, P1 transduction of btuB : :Tn 10 (from J.-P. Bohin, Orsay, France) resulted in replacement of the $\mathrm{Cm}^{\mathrm{R}} \mathrm{Ap}^{\mathrm{R}}$ phenotype by the $\mathrm{Tc}^{\mathrm{R}}$ phenotype and, second, $\mathrm{Btu}^{-}$and $\mathrm{Cm}^{\mathrm{R}} \mathrm{Ap}^{\mathrm{R}}$ were cotransducible. Four independent fusions were transferred into KL320 [metE his-29(Am) proB trpA605(Am) lacl3 lacZ118(Oc) gyrA $r p s L$; Birge \& Low, 1974] by P1 phage (Silhavy et al., 1984) with selection for $\mathrm{Cm}^{\mathrm{R}} \mathrm{Ap}^{\mathrm{R}}$ and subsequent screening for the $\mathrm{Btu}^{-}$phenotype. That a single copy of $\mathrm{Mu} \mathrm{dX}$, inserted in $b t u B$, was present was confirmed by showing that transduction of btuB : :Tn10 [source W3110 btuB460: :Tn10 from RK4936 (CGSC 6405) $\Delta(\arg F-l a \epsilon) 205$ metE70 
araD139 deoC relA1 non-9 fbB530 rpsL btuB460::Tn10] with selection for $\mathrm{Tc}^{\mathrm{R}}$ rendered the strains $\mathrm{Cm}^{\mathrm{S}} \mathrm{Ap}^{\mathrm{S}}$. rec $A$, met $H, o m p R$ and $m e t E^{+}$were introduced by P1 transduction from N3072 (recA::Tn $10 ; \mathrm{R}$. G. Lloyd, Nottingham, England), GW2537 [Ф(metE-lacZ)170 metH174: :Tn5 $\Delta($ lac $) U 169$ rpsL; Mulligan et al., 1982], PAP1402 (gyrA ompR885: :Tn5) and W3110 (wild-type), respectively. The F-prime F110 (btuB $B^{+}$) was transferred from AJ38 [argG metB lacZ58(Am) recAl rpsL F110 rpoB70 (RifR); Hayward et al., 1974] by mating. Strains AJP $150,350,450$ and 750 are the four fusion derivatives carrying rec $A$ and having the common genetic background KL320 recA : :Tn 10 btuB : : Mu dX. AJP $151,351,451$ and 751 , respectively, represent the F110 merodiploid derivatives. Similarly, AJP 361 and 461, AJP 156, 356, 456 and 756, and AJP 158, 358, 458 and 758 are the met $H:: \operatorname{Tn} 5, o m p R:: \operatorname{Tn} 5$ and $m e t E^{+}$derivatives, respectively. The presence of met $H$ was confirmed by the lack of growth on $10^{-6} \mathrm{M}$-vitamin $\mathrm{B}_{12}$. The $\operatorname{omp} R$ : : Tn5 strains were shown to be resistant to colicin $\mathrm{N}$, and to be deficient in OmpC and OmpF proteins. The latter was tested by SDS-PAGE of outer membranes prepared using the method of Pugsley \& Oudega (1986). $\beta$-Galactosidase assays were done according to Miller (1972) except that the cells were lysed with $50 \mu \mathrm{l} 0 \cdot 1 \%$ SDS and $100 \mu \mathrm{l}$ chloroform and cell debris was removed by centrifugation. The strains were grown at $37^{\circ} \mathrm{C}$ in L broth or minimal M9 medium (Maniatis et al., 1982) supplemented, as required, with histidine, tryptophan, proline, methionine and vitamin $B_{12}$. All results were obtained from duplicate assays done on three independent isolates.

\section{RESULTS AND DISCUSSION}

btuB-lacZ operon fusions were obtained in vivo using $\mathrm{Mu} \mathrm{dX}$ (lac $\mathrm{Cm}^{\mathrm{R}} \mathrm{Ap}^{\mathrm{R}}$ ). Four independently isolated $\mathrm{Lac}^{+}$fusions were transferred into $\mathrm{KL} 320 . \mathrm{Cm}^{\mathrm{R}} \mathrm{Ap}^{\mathrm{R}}$ transductants were selected and screened for inability to use exogenous vitamin $\mathrm{B}_{12}$, exploiting the fact that $m e t E$ mutants grow in the absence of methionine by virtue of the vitamin $B_{12}$-dependent homocysteine transmethylase (met $H$ product). The presence of $\mathrm{Mu} \mathrm{dX}$ in $b t u B$ was confirmed by showing that acquisition of $b t u B:: T n 10$ rendered the strains $\mathrm{Cm}^{\mathrm{s}} \mathrm{Ap}^{\mathrm{s}}$ (see Methods).

Exogenous vitamin $B_{12}$ reduced production of $\beta$-galactosidase in all btuB-lac $Z$ fusion strains (Fig. 1). In general, the maximum repression ratio - the ratio of $\beta$-galactosidase activity in the presence of the highest and lowest concentration of vitamin $B_{12}-$ was similar for all the fusions tested. The concentration of vitamin $B_{12}$ capable of reducing lac $Z$ expression depended upon whether a functional $b t u B$ gene was present. Thus, in fusions haploid for $b t u B$ and, consequently, lacking a functional BtuB receptor due to $\mathrm{Mu} \mathrm{dX}$ insertion, the inhibitory effect of exogenous vitamin $\mathrm{B}_{12}$ was only realized at concentrations in excess of $10^{-5} \mathrm{M}$. Introduction of a wild-type copy of btuB in trans on an F-prime plasmid (F110) allowed lower concentrations of exogenous vitamin $B_{12}\left(10^{-8} M\right.$ or greater) to exert an effect (in agreement with P. D. Moir, M. G. Hunter, J. T. Armstrong and R. E. Glass, unpublished results). The maximum repression ratio was the same in both a Btu ${ }^{-}$and $\mathrm{Btu}^{+}$background (Fig. 1).

These experiments led us to investigate the role of a number of gene products in the regulation of btuB. First, because $m e t H$ has been implicated in vitamin $\mathrm{B}_{12}^{-}$-dependent regulation of $m e t E$ (Mulligan et al., 1982), we introduced a metH : :Tn 5 allele into two of our fusion strains (AJP361, AJP461). Comparison of the repression ratio in a $\mathrm{MetH}^{-}$background (data not shown) demonstrated that the met $H$ gene did not play a major role, if any, in vitamin $B_{12}$-mediated regulation of $b t u B$. Similar experiments were conducted for $o m p R$ and $m e t E^{+}$, and similar results were obtained (data not shown); ompR and $m e t E$ did not affect $b t u B$ expression. omp $R$ was tested as it has been shown to be involved in the regulation of certain outer membrane proteins and because earlier results (Pugsley et al., 1983) suggested that $o m p R$ mutations affected colicin E2 and vitamin $B_{12}$ receptor activity. The absence of any effect of ompR on btuB expression in $L$ broth or minimal medium cultures was confirmed by demonstrating the same amounts of BtuB protein in the outer membranes of $o m p R$ and $o m p R^{+}$cells (data not shown). In the case of met $E$, we wanted to confirm that the presence of methionine in the growth medium (necessary for the growth of metE btuB double mutants) did not affect btuB expression.

Several other potential regulatory factors of $b t u B-l a c Z$ expression were examined. High osmolarity, local anaesthetics and $n$-alcohols are known to affect the expression of a number of genes coding for exported proteins (Pugsley, 1983). However, $300 \mathrm{~mm}-\mathrm{NaCl}, 15 \mathrm{~mm}$-phenethyl alcohol, $20 \mathrm{~mm}$-procaine, $350 \mathrm{mM}-n$-propanol and $70 \mathrm{mM}-n$-butanol were without effect on steady-state $b t u B-l a c Z$ expression in L broth cultures. Low temperature $\left(27^{\circ} \mathrm{C}\right)$ has also been reported to stimulate production of the BtuB protein (Lundrigan \& Earhart, 1984). However, we 


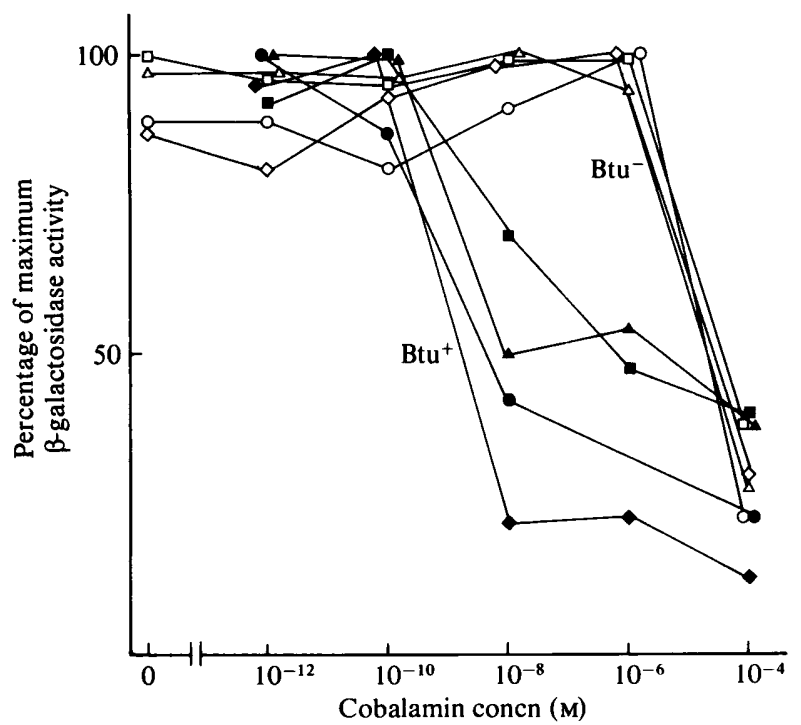

Fig. 1. Effect of exogenous cobalamin on $\beta$-galactosidase activity in four independently isolated $b t u B$ lacZ fusions. The data is for both Btu- $[A J P 150(\square), \operatorname{AJP350}(\triangle), \operatorname{AJP450}(\diamond)$ and AJP750 (O)] and

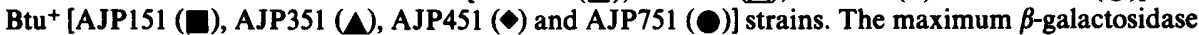
activity (in units) shown by the strains (AJP150, 101.7; AJP350, 93.9; AJP450, 90.4; AJP750, 185.6; AJP151, 98.4; AJP351, 60.2; AJP451, 46.9; AJP751, 78.3) suggests that the majority of the fusions are different. No $\beta$-galactosidase activity was found in the recA parent lacking a btuB-lacZ fusion. As a further control, we confirmed that $\beta$-galactosidase activity in a wild-type strain (W3110) was unaffected by the presence or absence of the concentration of vitamin $B_{12}$ employed $\left(10^{-4}\right.$ to $\left.10^{-12} \mathrm{M}\right)$.

were unable to reproduce this low-temperature regulation of BtuB protein; incubation temperatures in the range $24-37^{\circ} \mathrm{C}$ were without effect on btuB-lacZ expression (data not shown).

Our results confirm unambiguously that vitamin $B_{12}$ reduces expression of the $b t u B$ gene. Assuming no effect of translational control on $b t u B$ mRNA synthesis or stability (see Silhavy \& Beckwith, 1985), the observed vitamin $B_{12}$-dependent alteration in $\beta$-galactosidase activity may be interpreted to reflect regulation at the transcriptional level. Approximately $75 \%$ repression was observed, a figure in close agreement with the $80-90 \%$ reduction in vitamin $\mathrm{B}_{12}$ uptake capacity achieved in the presence of cobalamin (Kadner, 1978). That the concentration of exogenous vitamin $B_{12}$ giving this repression depended upon whether or not a functional BtuB receptor was present is in agreement with earlier work (Kadner \& Liggins, 1973) which showed that $E$. colibtuB mutants are only capable of taking up vitamin $B_{12}$ at concentrations of $10^{-6} \mathrm{M}$ or higher. Our results indicate that vitamin $B_{12}$-mediated regulation of $b t u B$ does not require the met $H$ product. Finally, we have shown that temperature, osmolarity, membrane pertubants, methionine, and $o m p R$ and $m e t E$ mutant alleles do not influence the regulation of btuB expression.

We should like to thank Nigel Bunce, Pete Moir and Geoff Rowland for their comments, and all those who sent strains. The work was supported in part by grants from the CNRS, MRC and the Wellcome Trust.

\section{REFERENCES}

Baker, T. A., Howe, M. M. \& Gross, C. A. (1983). Mu dX, a derivative of Mu dI (lac Ap ${ }^{\mathrm{R}}$ ) which makes stable lac $Z$ fusions at high temperature. Journal of Bacteriology 156, 970-974.

BIRGE, E. A. \& Low, K. B. (1974). Detection of transcribable recombination products following con- jugation in $\mathbf{R e c}^{+}, \mathrm{RecB}^{-}$and $\mathrm{RecC}^{-}$strains of Escherichia coli. Journal of Molecular Biology 83, 447457.

Chang, G. W. \& Chang, J. T. (1975). Evidence for the $B_{12}$-dependent enzyme ethanolamine deaminase in Salmonella. Nature, London 254, 150-151. 
Hayward, R. S., Austin, S. J. \& Scaife, J. (1974). The effect of gene dosage on the synthesis and stability of RNA polymerase subunits in Escherichia coli. Molecular and General Genetics 131, 173-180.

KADNER, R. J. (1978). Repression of synthesis of the vitamin $\mathrm{B}_{12}$ receptor in Escherichia coli. Journal of Bacteriology 136, 1050-1057.

KADNER, R. J. \& LigGINs, G. L. (1973). Transport of vitamin $B_{12}$ in Escherichia coli: genetic studies. Journal of Bacteriology 115, 514-521.

Lundrigan, M. D. \& Earhart, C. F. (1984). Strain and temperature-dependent variation in the amount of BtuB polypeptide in the Escherichia coli $\mathrm{K}-12$ outer membrane. FEMS Microbiology Letters 24, 341-344.

Maniatis, T., Frisch, E. F. \& SambrooK, J. (1982). Molecular Cloning: A Laboratory Manual. Cold Spring Harbor, NY: Cold Spring Harbor Laboratory.

Miller, J. H. (1972). Experiments in Molecular Genetics. Cold Spring Harbor, NY: Cold Spring Harbor Laboratory.

Mulligan, J. T., Margolin, W., Krueger, J. H. \& WALKER, G. C. (1982). Mutations affecting regulation of methionine biosynthesis genes isolated by use of met-lac fusions. Journal of Bacteriology 151, 609619.

Pugsley, A. P. (1983). Regulated OmpF porin synthesis in Escherichia coli K-12. FEMS Microbiology letters 20, 443-447.

Pugsley, A. P. \& Oudega, B. (1986). Methods for studying colicins and their plasmids. In Plasmids: $A$ Practical Approach (in the Press). Edited by $\mathbf{K}$. Hardy. Oxford: IRL Press.

Pugsley, A. P., Schwartz, M., Lavina, M. \& MORENO, F. (1983). On the effect of ompR on colicin E2 production. FEMS Microbiology Letters 19, 8792.

Silhavy, T. J. \& BeCKwith, J. R. (1985). Use of lac fusions for the study of biological problems. Microbiological Reviews 49, 398-418.

Silhavy, T. J., Borman, M. L. \& ENQuist, L. W. (1984). Experiments with Gene Fusions. Cold Spring Harbor, NY: Cold Spring Harbor Laboratory.

TAYLOR, R. T. \& WeISSBACH, H. (1967). N5-Methyltetrahydrofolate-homocysteine transmethylase. Partial purification and properties. Journal of Biological Chemistry 242, 1502-1508. 